\title{
Fate of Preharvest-Sprayed Dicofol in Date Fruits: Residue Analysis by HPLC-UV
}

\author{
S. Al-Rehiayani and K.A. Osman \\ Plant Production and Protection Department, College of Agriculture \\ and Veterinary Medicine, Al-Qassem University, Buraidah, \\ P.O. Box 1482, Saudi Arabia
}
مصير مبيد الدايكوفول على ثمار نخيل البلح: تحليل المتبقيات باستخدام جعاز التحليل الكروماتوجرافي عالي الأداء في نطاق.
الأشعة فوق البنفسجية المبندام جاز
سليمان الرحياني

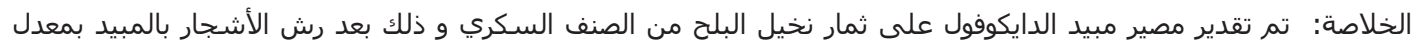

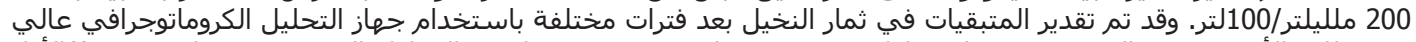

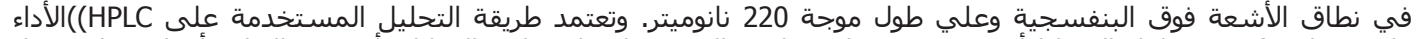
كانت خطية (قيمة معامل الارتباط أكبر من

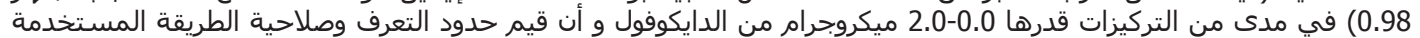

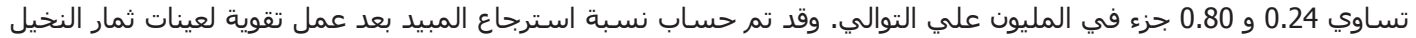

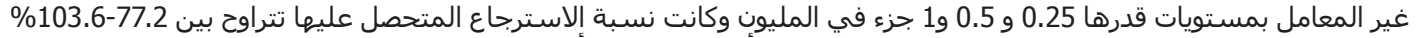

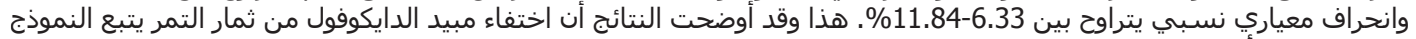

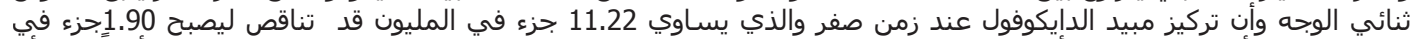

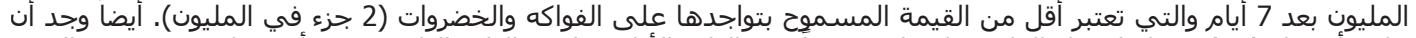

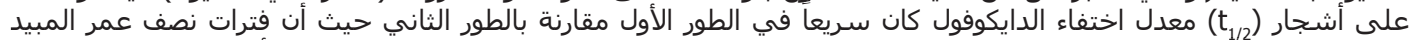

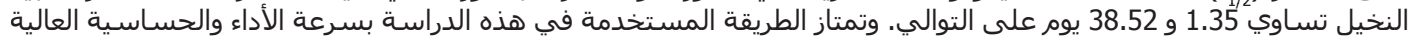
وارتفاع نسبة الاسترجاع مع إمكانية تكرار النتائج

ABSTRACT: The fate of pre-harvest-sprayed dicofol (DCF) on date fruits has been investigated. Date palm trees, variety Sukkari, were sprayed with DCF $(18.5 \%$, EC) at the rate of $200 \mathrm{ml} / 100 \mathrm{~L}$. DCF residues in date fruits were determined at different time intervals using high performance liquid chromatography (HPLC) with UV detection at $220 \mathrm{~nm}$. The method was based on extraction with ethyl acetate. The results showed that the HPLC response was linear $\left(\mathrm{r}^{2}>0.98\right)$ for DCF in the range of 0.0 to $2 \mathrm{~m} \mu \mathrm{g}$. The limits of detection and quantification were 0.24 and $0.80 \mathrm{ppm}$, respectively. The method was developed by using spiked date fruits at levels of $0.25,0.50$ and $1.0 \mathrm{ppm}$. Recovery percentage was satisfactory with a range of 77.2 to $103.6 \%$ and an RSD ranging from 6.33 to $11.84 \%$. A biphasic model was assumed in order to carry out the statistical study of the loss of DCF from date fruits. The results showed that the initial deposit of DCF on date fruits was $11.22 \mathrm{ppm}$, while the residue value decreased to $1.90 \mathrm{ppm}$ seven days after spraying, which is below the tolerance limit for fruits and vegetables (2 ppm). Also, the data indicate that there was a faster rate of DCF loss in the first phase than the second one. This is clearly reflected in the $\mathrm{t}_{1 / 2}$ values, where the half-lives of DCF were 1.35 and 38.52 days, for the first and second phase model, respectively. The described method is rapid and sensitive, with satisfactory recoveries and reproducibility.

Keywords: Date fruits, fate, dicofol, residue, limit of detection, half-life

\section{Introduction}

Pesticides are widely used in agriculture to control a variety of pernicious organisms that spoil crops. More than 600 kinds of agrochemicals are used around the world (Miyake et al., 1999). They provide unquestionable benefit for agricultural production, even though, as a consequence, low amounts of some residues may persist in the food supply and could constitute a significant exposure pathway for humans. Exposure to food residues has created uncertainty for potential chronic toxicity and, in some cases, acute toxicity (Saunders and Harper, 1994; Ekström et al., 1996; Osman and Al-Rehiayani, 2003).

\footnotetext{
$\overline{* \text { Corresponding author }}$
} 
The use of chlorinated hydrocarbon insecticides has been sharply curtailed or banned, but they are still the active ingredients of some pest control products (Moore, 1986). For example, dicofol (DCF) is used world-wide as a pre-harvest miticide on cotton, citrus, vegetable, nuts and other crops (Rohm and Hass, 1984; Mourer et al., 1990; Fernăndez et al., 2001; Kitajama et al., 2003). DCF is structurally similar to DDT, which is used as the starting material for synthesis for DCF (Wiemeyer et al., 2001). The US-EPA became concerned about the continued use products containing DCF because they also contained DDT and related compounds (Moore, 1986). DCF products marketed after May 1986 could contain no more than $2.5 \%$ DDT and related compounds and those marketed after 1988 could have no more than $0.1 \%$ DDT and related compounds. Following reassessment of dietary risk, the EPA has updated U.S. tolerances for DCF residues on a variety of crop commodities and described harmonization with Codex MRLs (U.S.-EPA, 1998).

Al-Qassem region is one of the largest agricultural areas in the Kingdom of Saudi Arabia and much of its arable and fertile land is under date palms (Phoenix dactylifera L.). Al-Qassem community produces the majority of date fruits consumed locally and much of those exported outside the country. During the 2002 season, date fruit production was greater than 130,000 tons, of which approximately 1,092 tons were destined for export (Saudi Ministry of Agriculture and Water, 2003). Expansion in date fruit production has brought about increasing pest problems. Pest control has been achieved by heavy reliance on injudicious and indiscriminate use of broad-spectrum pesticides. Consequently, unacceptable concentrations of pesticide residues have been found in date fruits (AlRehiayani and Osman, 2003).

DCF is often applied to date palms in Saudi Arabia at a rate of $200 \mathrm{ml} / 100 \mathrm{~L}$ to control mites. Unfortunately, no data are available on DCF residues and its loss on date fruits, although it has been reported in cucumber (Nazer and Masoud, 1986), fish (Barbera, et al., 1986), meat (Yossef et al., 2003), avian eggs (Krynitsky et al., 1988) and citrus (Fernăndez et al., 2001; Torres et al., 1996; Saitta et al., 2000). Because fruits of the date palm are vital components of the diet in Saudi Arabia, consumers are increasingly concerned about DCF residues in date fruits and their carry-over to processed products.
Quantitative methods for DCF determination in agricultural products have been reported using colorimetry (Rosenthal et al., 1957), ultra-violet spectrophotometry (Gunther and Blinn, 1957), gas liquid chromatography using an electron capture detector, (Morgan, 1967; Ribeiro et al., 2000) or mass selective detection (Soleas et al., 2000) and high performance liquid chromatography (Fernăndez et al., 2001) The difficult and crucial step in pesticide residue analysis of complex media, such as foods, is the clean-up or separation of chemicals of interest. In this study, clean-up, separation and determination of the optimum conditions for $\mathrm{p}, \mathrm{p}$-DCF analysis in date fruits were developed. Also, the present study was carried out to determine the residue levels of DCF at different time intervals following field application, as well as the half-life $\left(t_{1 / 2}\right)$ on date fruits.

\section{Materials and Methods}

Dicofol (DCF), [2,2,2-trichloro-1,1-bis-(4-chlorophenyl) ethanol], (18.5\% EC) was purchased from Hockly International Company, UK, while technical DCF was provided by Environmental Protection Agency (EPA, USA) with a purity of $99 \%$. Certified HPLC-grade ethyl acetate, methanol, acetonitrile (ACN) and granular AR anhydrous sodium sulfate were purchased from BDH Company, while Florisil (60-100 mesh) was purchased from Riedel-de Haën (Germany). Deionized water of $15 \mathrm{MW} \Omega . \mathrm{cm}$ resistivity was obtained from a water purification system (PURELAB Option-R, ELGA, UK). All solvents and solutions were passed, before used, through a $0.45 \mathrm{~m} \mu \mathrm{m}$ sterile disposable nylon filter (AcroCp, Gelman Sciences).

Sukkari, the most widely grown date variety in Al-Qassem region, was selected for this study. Date palm trees cultivated in El-Soltan Farm, north of ElMeledia District, Al-Qassem area, Saudi Arabia, were arranged in a randomized design and sprayed at the end of May 2002 with DCF (18.5\% EC) at the rate of $200 \mathrm{ml} / 100 \mathrm{~L}$ ( $37 \mathrm{~g}$ active ingredient, a.i./100 L) using a motorized sprayer that was calibrated to deliver 10 $\mathrm{L} /$ tree. Treatments were done in triplicate with eight trees assigned to each replicate. Untreated trees were sprayed only with water and used as analytical controls for background residues and for fortification recovery studies. Date fruits were collected 0, 2 and $4 \mathrm{hrs}$ and 1, $2,4,7,14,21,28,42$ and 56 days after DCF application 
to determine residue concentration. Samples were immediately transported to the laboratory and kept at $-15^{\circ} \mathrm{C}$ until residue analysis.

Three 50-g aliquots of date fruits from each time interval were chopped and placed in a $250-\mathrm{ml}$ conical flask and blended with $100 \mathrm{ml}$ ethyl acetate for $2 \mathrm{~min}$. The homogenate was then filtered under vacuum through Whatman No. 2 filter paper. The solids were re-extracted with $100 \mathrm{ml}$ ethyl acetate for another $2 \mathrm{~min}$. The combined, filtered extract was passed through a funnel containing anhydrous sodium sulfate, evaporated using a rotary evaporator $\left(38^{\circ} \mathrm{C}\right)$ to ca. $2 \mathrm{ml}$ and then made up to $5 \mathrm{ml}$ with ethyl acetate. The concentrated extract was passed through a glass chromatographic column ( $20 \mathrm{~cm} \times 10 \mathrm{~mm}$ i.d.) packed in sequence from bottom to top, with glass wool, 10 $\mathrm{g}$ of activated Florisil and topped with $2 \mathrm{~g}$ anhydrous sodium sulfate. The column was pre-washed with ethyl acetate. The extract was added to the column and eluted with $50 \mathrm{ml}$ of ethyl acetate. The eluent was evaporated to dryness using a gentle stream of nitrogen and redissolved in $10 \mathrm{ml}$ methanol. The final solution was filtered through a $0.45 \mathrm{~m} \mu \mathrm{m}$ sterile disposable nylon filter prior to HPLC analysis.

The HPLC system was standardized on the same day as the samples were analyzed by injecting $20 \mu \mathrm{l}$ of eight solutions of freshly prepared DCF in methanol with concentrations ranging from 0.0 to $10 \mathrm{ppm}$ from a stock solution of $1000 \mathrm{ppm}$. Areas under the peak $(\mathrm{uV} . \mathrm{sec})$ versus concentrations $(\mu \mathrm{g})$ were plotted and simple linear regression used to obtain an equation for the standard curve. The amount of DCF in each sample was thus calculated based on the slope of the standard curve.

Three 50-g aliquots of the untreated control were treated as individual replicates for a DCF fortification recovery study. Spiking was done at the levels of $0.25,0.50$ and $1.0 \mu \mathrm{g} / \mathrm{g}$ (ppm). In addition to the spiked samples, one date fruit blank and one solvent blank were run concurrently with the extraction set. Recoveries for DCF and relative standard deviation (RSD) were calculated after HPLC analysis.

Extracts were chromatographed on a Perkin Elmer HPLC system model 200 equipped with a degasser, quaternary LC pump model 2000Q/410, $20 \mu \mathrm{l}$ loop, Spheri-5 RP-18 column ( $25 \mathrm{~cm} \times 4.6 \mathrm{~mm}$ i.d., $5 \mu \mathrm{m}$, Perkin Elmer), oven column, a LC200 UV detector. The Turbochrom Workstation Software package was used for instrument control, data acquisition, and data analysis. The column temperature was kept at $25{ }^{\circ} \mathrm{C}$. DCF was eluted using an isocratic gradient of $78: 22 \mathrm{v} / \mathrm{v}$ ACN:H2O. DCF was detected by scanning the eluent at wavelengths $(1 \lambda)$ from 200 to $260 \mathrm{~nm}$ at a flow rate of $1.1 \mathrm{ml} / \mathrm{min}$. The retention time for DCF was 10.4 $\min$.

The detection (LOD) and quantification (LOQ) limits with this procedure were defined as the concentration of the DCF in date fruits (expressed as ppm) that gave signals of 3 and 10 times the noise, respectively, within its retent on time (tR) window (Falqui-Cao et al., 2001). Corresponding results were compared with the maximum residue limit.

The data were calculated as mean \pm \pm S.D and analyzed using analysis of variance technique (ANOVA). Probability of 0.05 or less was considered significant. All statistical analysis was done with Costat Program (Version 2, CoHort Software, 1986).

\section{Results and Discussion}

The HPLC response was linear $\left(r^{2}>0.98\right)$ for DCF in the range of 0.0 to 2 microgram $(\mu \mathrm{g})$. The LOD of DCF in date fruits was $0.24 \mathrm{ppm}$ or about 8.3 times lower than the maximum residue limit (MRL) of $2 \mathrm{ppm}$. In a study of DCF residues on oranges, the LOD by GC-ECD analysis was also reported to be 0.24 ppm (Fernăndez et al., 2001). In a multi-residue study of matrix solid phase dispersion extraction of oranges followed by detection with GC-ECD, the LOD for DCF was 0.010 ppm (Torres et al., 1996). The LOQ determined from the method validation was $0.80 \mathrm{ppm}$. Interferences from co-extractives raise the LOQ of a method by masking the detector response to the residue or by preventing injection of the specified sample matrix without undesirable damage to the system (Falqui-Cao et al., 2001). Additional procedures to clean the sample extract prior to determination may improve the LOQ by removing these interferences. Column cleanup in this study was needed to remove coextractives from date extracts prior to HPLC. The Florisil elution system used in the present study efficiently isolated DCF from the coextractives, where a few unknown peaks appeared in HPLC chromatograms due to coextractives, but did not interfere with DCF peak.

Results of the recoveries of spiked samples are summarized in Table 1. Recovery percentage was satisfactory with a range of 77.2 to $103.6 \%$ and an 
Table 1. Mean recoveries of DCF from spiked date fruits.

\begin{tabular}{cccc}
\hline $\begin{array}{l}\text { Amount } \\
\text { Spiked } \\
(\mathbf{p p m})\end{array}$ & $\begin{array}{c}\text { No. of } \\
\text { Determi- } \\
\text { nations }\end{array}$ & $\begin{array}{c}\text { Recovery } \\
(\%)\end{array}$ & $\begin{array}{c}\text { RSD } \\
(\%)\end{array}$ \\
\hline 0.25 & 3 & 103.6 & 6.33 \\
0.50 & 5 & 77.2 & 11.48 \\
1.00 & 3 & 89.6 & 8.98 \\
\hline
\end{tabular}

RSD ranging from 6.33 to $11.84 \%$. The results are in agreement with the extraction efficiencies reported by other authors who found that the mean recoveries for DCF ranged from 77.2 to $93.8 \%$ in egg yolk (Mourer et al., 1990), 78 to $104 \%$ in tea (Zhu and Wang, 2000) and 87 to $95 \%$ in oranges (Ribeiro et al., 2000). The percentage recoveries for the present study can be considered satisfactory according to guidelines which state that any method with a proven recovery of $70 \%$ or more could be eligible for future official adoption (Schuller et al., 1976). Also, the low RSDs indicated a high level of repeatability for the tested method.

Data in Table 2 illustrate the levels of DCF in date fruits over a period of 56 days following one application of DCF at rate of $37 \mathrm{~g}$ a.i./100 L. Initial DCF residues were 11.22 ppm but decreased by 78,66 , 60,46 and $18 \%$ of the initial deposit after 2, 4, 24, 48 and 96 hrs, respectively, following application. From day 4 on, the decrease was slow with non significant differences between the residue levels of DCF.

Although MRLs have been established for registered pesticides on agricultural commodities to guarantee their proper use and adequate control (Council Directive, 1990), no maximal limit of DCF residues has been established on date fruits. The residue level 7 days after DCF spraying was 1.90 ppm which is less than the maximum residue limits for fruits and vegetables of 2 ppm (Fernăndez et al., 2001). Also, data in Table 2 illustrate that less than $9 \%$ of the initial deposit was detected during the period of 4-8 weeks after DCF application. The present results are consistent with another investigation, where DCF residues on cucumber fruits were below the tolerance level of 2 ppm and no residue could be detected 8 days after DCF application under either plastic house or plastic tunnels (Nazer and Masoud, 1986).

The rate of loss of DCF residue from date fruits is presented in Figure 1. A biphasic model was assumed
Table 2. DCF residues in pre-harvest-sprayed date fruits after different time intervals.

\begin{tabular}{|c|c|c|c|}
\hline $\begin{array}{l}\text { Time } \\
\text { Interval } \\
\text { (days) }\end{array}$ & $\begin{array}{c}\text { DCF Level } \\
\quad(p p m) \\
\text { Mean } \pm \text { S.D* }\end{array}$ & $\begin{array}{c}\text { Initial } \\
\text { Deposit } \\
(\%)\end{array}$ & $\begin{array}{c}\text { Relative } \\
\text { Standard } \\
\text { Deviation } \\
\text { (RSD) } \\
(\%)\end{array}$ \\
\hline 0 & $11.22 \pm 1.53^{\mathrm{d}}$ & 100.00 & 13.64 \\
\hline $2 / 24$ & $8.71 \pm 0.72^{\mathrm{c}}$ & 77.66 & 8.27 \\
\hline $4 / 24$ & $7.38 \pm 0.42 b^{c}$ & 65.78 & 5.69 \\
\hline 1 & $6.69 \pm 0.97^{\mathrm{bc}}$ & 59.63 & 14.50 \\
\hline 2 & $5.19 \pm 0.75^{b}$ & 46.26 & 14.45 \\
\hline 4 & $2.07 \pm 0.14^{\mathrm{a}}$ & 18.45 & 6.76 \\
\hline 7 & $1.90 \pm 0.14^{\mathrm{a}}$ & 16.93 & 7.37 \\
\hline 14 & $1.76 \pm 0.14^{\mathrm{a}}$ & 15.69 & 7.95 \\
\hline 21 & $1.25 \pm 0.07^{\mathrm{a}}$ & 11.15 & 5.60 \\
\hline 28 & $0.99 \pm 0.01^{\mathrm{a}}$ & 8.82 & 1.01 \\
\hline 42 & $0.93 \pm 0.09^{\mathrm{a}}$ & 8.29 & 9.73 \\
\hline 56 & $0.67 \pm 0.09^{\mathrm{a}}$ & 5.97 & 13.43 \\
\hline
\end{tabular}

* Results are expressed as means \pm standard deviations (S.D). Means in a column with different coefficients (a-d) are significantly different $\left(\mathrm{p} \leq 0.05\right.$ and $\mathrm{LSD}_{0.05}$ is 1.79).

in order to carry out the statistical study of the loss of DCF according to equation (1).

$$
\mathrm{R}=\mathrm{A}_{0} \mathrm{e}^{-\mathrm{a} \alpha \mathrm{t}}+\mathrm{B}_{0} \mathrm{e}^{-\mathrm{b} \beta \mathrm{t}}
$$

where $\mathrm{R}$ is residue level at $\mathrm{t}$ days, $\mathrm{A}_{0}$ and $\mathrm{B}_{0}$ are the residue concentrations at $\mathrm{t}=0$ and $\mathrm{a} \alpha$ and $\mathrm{b} \beta$ are the loss rate constants for the first and second phase model,

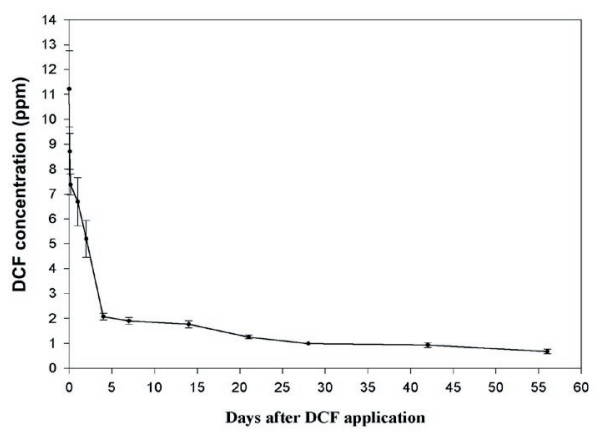

Figure 1. Dissipation curve for DCF. Data are expressed as means \pm \pm S.D $(n=3)$. 
Table 3. Statistical parameters of DCF dissipation from treated date fruits.

\begin{tabular}{lr}
\hline Statistical Parameters & Value \\
\hline $\mathrm{A}_{0}(\mathrm{ppm})$ & 7.71 \\
$\mathrm{~B}_{0}(\mathrm{ppm})$ & 1.85 \\
$\mathrm{a} \alpha\left(\right.$ day ${ }^{\mathrm{s}-1}$ & 0.51 \\
$\mathrm{~b} \beta\left(\right.$ day $^{\mathrm{s}-1}$ & 0.02 \\
$\mathrm{~T}_{1 / 2 \mathrm{a}} \alpha$ (days & 1.35 \\
$\mathrm{~T}_{1 / 2 \mathrm{~b}} \beta$ (days & 38.52 \\
Regression coefficient & 0.98 \\
\hline
\end{tabular}

respectively. The half-life $\left(t_{1 / 2}\right)$ of the exponential decay was calculated according to equation (2).

$$
t_{1 / 2}=(2.303 \log 2) / \text { rate constant }
$$

The data indicate that there was a faster rate of DCF loss in the first phase than the second one (Table 3 ). This is clearly reflected in the $t_{1 / 2}$ values, where the half-lives of DCF in date fruits were estimated to be 1.35 and 38.52 days, for the first and second phase models, respectively.

\section{Conclusion}

Although dicofol disappears rapidly from date fruits where the residue level 7 days after DCF spraying was $1.90 \mathrm{ppm}$, less than the maximum residue limits for fruits and vegetables of $2 \mathrm{ppm}$, pesticide residue monitoring programs should nevertheless be implemented to ensure minimal residue levels in date fruits and to check compliance with the existing regulations. Also, the described procedure is simple and less labor intensive and troublesome emulsions, such as those frequently observed in liquid-liquid partitioning, did not occur. Further, these were satisfactory recoveries. The sensitivity of detection of DCF in the present study was $0.24 \mathrm{ppm}$, which is equivalent to that obtained by Fernăndez et al. (2001) when DCF was analyzed by GC-ECD.

\section{References}

Al-Rehiayani, S. and K.A. Osman. 2003. Residual levels of preharvest-sprayed amitraz in date fruits. Journal of Pest Control and Environmental Sciences 11:1-12.

Barbera, J.C., F.J. Lopez, F. Hernandez, J. Medina and A. Pastor. 1986. Gas chromatographic determination of organochlorine pesticides; contamination of dicofol, fenson, and tetradifon in fish and natural waters of a water area beside the Mediterranean Sea. Bulletin of Environmental Contamination and Toxicology 36: 211-218.

Council Directive. 1990. Council Directive 90/642/EEC of 27 November 1990 on the fixing of maximum levels of pesticide residues in and on certain products of plant origin, including fruit and vegetables. Official Journal of the European Communities L350:71-118.

Costat Program. 1986. Version 2, Cohort Software.

Ekström, G., H. Hemming, and M. Palborg. 1996. Swedish pesticide risk reduction 1985-1995: Food residues, health hazard and reported poisoning. Reviews of Environmental Contamination and Toxicology 147:119-139.

Falqui-Cao, C., Z. Wang, L. Urruty, J.J. Pommier and M. Montury. 2001. Focused microwave assistance for extracting pesticide residues from strawberries into water before their determination by SPME/ HPLC/DAD. Journal of Agricultural and Food Chemistry 49:5092-5097.

Fernăndez, M., Y. Pico and J. Manes. 2001. Pesticide residues in oranges from Valencia (Spain). Food Additives and Contaminants 18:615-624.

Gunther, F.A. and R.C. Blinn. 1957. Ultraviolet spectrophotometeric microdetection of the acaricide 4,4'-dichloro-alpha-(trichloromethyl) benzhydrol (SW-293). Journal of Agricultural and Food Chemists 5:517-519.

Kitajama, E.W., J.A. Rezende and J.C. Rodrigues 2003. Passion fruit spot virus vectored by Brevipalpus phoenicis (Acari:Tenuipalpidae) on passion fruit in Brazil. Experimental and Applied Acarology 30:225-231.

Krynitsky, A.J., C.J. Stafford and S.N. Wiemeyer. 1988. Combined extraction-cleanup column chromatographic procedure for determination of dicofol in avian eggs. Journal of the Association of Official Analytical Chemists 71:539-542.

Miyake, Y., K. Koji, H. Matsuki and R. Tajima. 1999. Fate of agrochemical residues, associated with malt and hops. Journal of American Society of Brewing Chemists 57:46-54.

Moore, J.A. 1986. Dicofol: Intent to cancel registrations of pesticide products containing dicofol: Denial of applications for registration of pesticide products containing dicofol: Conclusion of special review. Notice of final determination. U.S. Federal Regulations 51:19508-19525. 
Morgan, N.L. 1967. The identification and relative retention times of $p, p$ '-kelthane and its breakdown product p,p'-dichlorobenzophenone using GLC. Bulletin of Environmental Contamination and Toxicology 2:306-312.

Mourer, C.R., G.L. Hall, W.E. Whitehead, T. Shibamoto, L.R. Shull and S.E. Schwarzbach. 1990. Chromatographic determination of dicofol and metabolites in egg yolks. Archives of Environmental Science and Health 19:154-156.

Nazer, I.K. and H.A. Masoud. 1986. Residues of dicofol on cucumber grown under plastic covers in Jordan. Journal of Environmental Science and Health 21:387-399.

Osman, K.A. and S. Al-Rehiayani. 2003. Risk assessment of pesticide to human and the environment. Saudi Journal of Biological Sciences 10:81-106.

Ribeiro, M.L., J.R. Amador, L. Polese, E.F. Jardim, E.V. Minelli and O.C. de Cordis. 2000. Effect of a pilot washing system on dicofol levels in orange matrix. Journal of Agricultural and Food Chemistry 48:2818-2820.

Rohm and Hass Company. 1984. Important information regarding kelthane miticide, its role in agriculture, its impact on the environment and the issue of DDT. Philadelphia, PA, USA.

Rosenthal, J., G. Frisone and F.A. Gunther. 1957. Colorimetric microdetermination of the acaricide 4,4'-dichloro-alpha-(trichloromethyl) benzhydrol (FW-293). Journal of Agricultural and Food Chemistry 5:514-517.

Saitta, M., Bella, G.Di., Salvo, F., Curto, S. Lo., and Dugo, G. 2000. Organochlorine pesticide residues in Italian citrus essential oils, 1991-1996. Journal of Agricultural and Food Chemistry 48:797-801.

Saudi Ministry of Agriculture and Water. 2003. Statistical Predictions about Agriculture in Al-Qassem Region, Volume 5, Department of
Statistical and Economic Researches: Agriculture Administration, Al-Qassem, Saudi Arabia.

Saunders, D.S. and C. Harper. 1994. Pesticides. In: Principles and Methods of Toxicology. A.W. Hays (Editor), 389.

Schuller, P.L., W. Horwitz and L. Stoloff. 1976. A review of sampling plants and collaborative studies method of analysis for aflatoxin. Journal of the Association of Official Analytical Chemists 59:1315-1343.

Soleas, G.J., Yan, J.H., K., and Goldberg, D.M. 2000. Multiresidue analysis of seventeen pesticides in wine by gas chromatography with mass-selective detection. Journal of Chromatography 882:205212.

Torres, C.M., Y. Pico, M.J. Redondo and J. Manes. 1996. Matrix solid-phase dispersion extraction procedure for multiresidue pesticide analysis in oranges. Journal of Chromatography 719:95-103.

U.S.-EPA. 1998. Registration Eligibility Decision (RED)-Dicofol. EPA 738-R-98-018, November 1998.

Wiemeyer, S.N., D.R. Clarck, Jr., J.W. Spann, A.A. Belise and C.M. Bunck. 2001. Dicofol residues in eggs and carcasses of captive American kestrels. Environmental Toxicology and Chemistry 20: 2848-2851.

Yossef, H., A. Al-Qarawi, H. Mousa, K.A. Osman and H. Abdel-Rahman. 2003. Organochlorine residues in carcasses of camels slaughtered in Al-Gassem Region, Saudi Arabia. In: Deutsche Veterinärmedizinische Gesellschaft 44. Tagung des Arbeitsgebietes Lebensmittelhygiene der Deutschen Veterinärmedizinischen Gesellschaft. Garmisch-Partenkirchen.

Zhu, M.X. and Y. Wang. 2000. Determination of dicofol residue in tea by wide-bore capillary gas column. Se Pu. 18:64-66.

Received: December 2004

Accepted: April 2005 